\title{
Mechanical and structural investigations of wings of selected insect species
}

\author{
Michą LANDOWSKI ${ }^{1}$, ZUZANNA KUNICKA-KOWALSKA ${ }^{2}$, KRZYSZTOF SibILSKI ${ }^{3 *}$ \\ ${ }^{1}$ Gdańsk University of Technology, Faculty of Mechanical Engineering, \\ Department of Materials Engineering and Bonding; Gdańsk, Poland. \\ ${ }^{2}$ Warsaw University of Technology, Doctoral School No. 4, Warsaw, Poland. \\ ${ }^{3}$ Warsaw University of Technology, Faculty of Power and Aeronautical Engineering, \\ Division of Mechanics, Warsaw, Poland.
}

\begin{abstract}
This paper presents research and measurements leading to obtaining the Young's modulus of wing bearing structures of selected insect species. A small testing machine intended for three-point bending and equipped with instruments registering low forces was constructed for the needs of the experiment. The machine was used to perform numerous bending tests of wings of three species of insects (obtained from a breeding farm): Attacus atlas, Vespa crabro, Libellula Depressa at various air-humidity conditions. Values of the force and displacement obtained in the course of the tests were used to calculate Young's modulus. In order to do so, it was also necessary to obtain the moment of inertia of the wing cross-section. These values were measured on the basis of the images obtained with a SEM microscope. Obtained results were averaged and presented with a breakdown by air-humidity conditions. It was observed that Young's modulus decreased with an increase of humidity, hence the calculations of the percentage decrease of this mechanical parameter were performed. Obtained results were compared with the observed structure which was also presented under light microscope. It transpired that the construction of a wing does not only influence the mechanical values but also it influences their susceptibility to the changes occurring in the environment. Thereby, differences between Lepidoptera and Hymenoptera insects were indicated also within the aspect discussed in this paper.
\end{abstract}

Key words: insect wing structure, insect wing materials, strength of insect wings

\section{Introduction}

Research falling within the material science which have been performed so far focused mostly on the structure of insects wings instead of their strength parameters. Wings structures were examined, with a microscope as well, by scientists representing various disciplines, aiming at the description of the construction of a wing [15], [19], [25]. Le Roy [17] described the variation of wing shape caused by adaptation in evolution process. Some of these works attempt to recreate or mimic the wings, their deformations during flight or the frequency of natural vibrations, even with the application of the FEM method [27], [20], [13].
Others try to produce a material (a composite one, usually) reflecting the mechanical parameters and structure of the insect wings [1], [10] or even construct a Biomimetic Micro Aerial Vehicle (BMAV) that is a flying vehicle mimicking not only biological materials but also the way insects move [25], [12], [22]. A significant part of scientists focuses solely on examining the construction of the wings of Lepidoptera insects. Microstructure of the particular scales and their fixings as well as the implication of such a construction are the subjects of numerous research and, at the same time, give hope of obtaining interesting results [4], [5], [24], [21]. In the articles [3], [18], [23], material properties of insect wings built only from veins and membrane were conducted. The research

* Corresponding author: Krzysztof Sibilski, Warsaw University of Technology, Faculty of Power and Aeronautical Engineering, Division of Mechanics, ul. Nowowiejska 24, 00-665, Warsaw, Poland. Phone: 0048604417540, e-mail: sibilski@hot.pl

Received: December 14th, 2019

Accepted for publication: May 13th, 2020 
described in this paper clearly shows that the characteristics of these properties in Lepidoptera are different. In addition, thanks to the conducted analyzes, it can be clearly demonstrated that the flexibility of insect wings is highly dependent on the ambient humidity. Therefore, the proper value of the Young's modulus for a given wing should be considered the module tested in such humidity conditions that are present in the place of occurrence of a given species. None of the articles abovemention, this important parameter. There are plans of taking the advantage of the knowledge on the influence of the scale structure on the colours of a wing. Among others, an example of Morpho butterfly was used to examine the method of reflecting white light of a scale in order to identify the method of creating a unique gloss on the wing. This knowledge can be used in manufacturing solar cells. There are also research projects which directly deal with the flexion of a wing and joints of its structures depending on the species of an insect [9]. As far as the research of insect wings is concerned, dragonflies and butterflies are most gladly used, followed by beetles. The latter constitute a very interesting case for flight mechanics, since one pair of wings evolved into elytron (wing covers) and in majority of species it is a fixed bearing surface, while the wings act as a propeller [8].

Despite interesting and profound analyses, in the vast majority, the researches did not lead to obtaining reliable mechanical parameters. It is even harder because insect wings are natural composites and belong to anisotropic materials. Basically, the wings are constructed of veins which act as supporting frame and membrane spanning between these veins. The veins are placed in an irregular manner (neither longitudinal, nor transverse, at times almost radial - butterflies) [8]. What is more, each vein slightly differs in terms of construction. Individual features are also important. In the article [18], the bending test was carried out by attaching the wing at the point of its rotation and applying force at a distance of 0.7 of the chord from this point. This led to an average result. Similarly, in the studies described here, half-leading and half-trailing experiments were performed to obtain the average Young's modulus - veins reduce the cross-section as the distance from the rotation point increases. Studies differ in the method of attachment, but both tend to obtain an average result, because only such one is possible in the case of different biological materials. In the case of large wings, it is possible to examine a specific section of a wing, while small wings need to be examined as a whole, without zonal division. This requires constructing a testing machine with equip- ment allowing bending specimens which are several hundred micrometers long and force sensors of a very small range. In their paper, Jiyu Sun and Bharat Bhushan [26] describe the construction of a dragonfly wing. They publish the photographs of the crosssections depending on the distance between the cross section and insect body along with the table containing mechanical properties: Young's modulus and the hardness of various elements of wings. It is, however, the only such a vast source of data and it refers to one order of insects only. Additionally, the values are significantly diversified, depending on the wing element and measurement method. The research was performed with a nanoindenter which uses a diamond indenter to determine mechanical properties and defines the characteristics on the basis of nano-hardness measurements. Insect wings, being a natural composite, have a complex construction, which is why determining the properties of a wing on the basis of the properties of the component materials without the influence of the reinforcement distribution and shape causes significant discrepancies with the real mechanical properties of the wings. Nevertheless, the data can be a used as a certain reference point and allow for the verification of the correctness of performed experiments. Numerous literary sources contain information on the relationship between mechanical properties and condition of the insect wings. Young's modulus value of a fresh membrane of an Allomyrina dichotoma hindwing ranges from 2.97 to $4.5 \mathrm{GPa}$ [14]. Compared with the fresh hindwing, the Young's modulus value of the dry membrane of a Allomyrina dichotoma hindwing is lower and varies over the area of the wing and ranges from 2.06 to $2.74 \mathrm{GPa}$ [9]. These results suggest the necessity of selecting the air humidity conditions which will allow for performing the research on mechanical properties compliant with the conditions of the insects habitats. Only the results of mechanical examinations performed in conditions which are similar to the real ones will allow for using them in simulation of the wing movement and yield correct outcomes. Insect wings are made of composite materials - natural composites. Years of evolution have affected the proper distribution of reinforcements and optimal use of material [17], which encourages the use of solutions in the design of composites. In aviation constructions, often used are composite materials whose advantages over conventional materials are obvious [16]. The aim of the work was to obtain reliable material data necessary to describe the flight mechanics and create a MAV prototype. Ultimately, the material data obtained is to be used for the FSI (Fluid Structure Interaction) numerical calculations to 
model the interaction of the wing and the airflow around it. The next stage is the possibility of using the information obtained in this way to implement it in the entomopter (micro air vehicle modeled on the flight of insects). These types of devices allow for low-speed flight in low pressure conditions. An increase in flap frequency increases the lift. This solution can be used at high altitudes or as part of rover equipment in space missions. An example of such a concept is the NASA entomopter (NIAC team) [7].

\section{Materials and methods}

Due to the lack of appropriate measuring devices, in order to examine the insect wings, a special testing machine adapted for biological material tests was designed and constructed. The appropriate selection of the components parameters was necessary because of low forces breaking the material and small sizes of the specimens. The machine consisted of two basic parts:

- structural part: main frame made of aluminium profiles ensuring the appropriate stiffness, linear actuator and adjustable grip for the test of 3-point bending, made of S355 structural steel;

- measurement part: force and displacement sensor with data acquisition system.

The initial design of the machine was made in Inventor software. The design, which can be seen in Fig. 1, did not assume the final selection of the elements, but rather aimed at specifying the dimensions and outline of the construction. Initially it was assumed that the displacement will be achieved with a gearbox transmission, however, an electrical linear actuator was used in the final version.

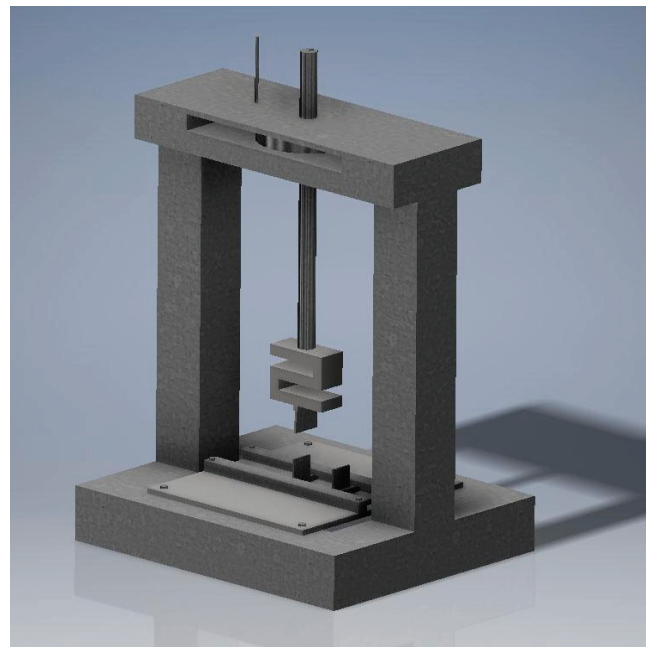

Fig. 1. Initial concept and 3D outline of the machine
The main frame was made of $30 \mathrm{~mm}$ wide aluminium profiles featuring four T-slots, joined together with bolts and angle brackets to form the frame construction. Aluminium profiles used in construction ensured the stiffness of the structure due to their appropriate cross-section which translates into more precise results of the forces and displacement measurements. Using special profiles allowed for fixing the elements with T-head bolts and arbitrary reconfiguration of the measurement system. Special cuts in the T-head of the bolts ensured self-locking and allowed the penetration of the oxide layer on the profile surface, which ensured better dissipation of static electricity. Static electricity accumulated on the operator can significantly impede the measurements or even cause the damage of the measurement system. Electronic components in measurement system are powered by the current of $5 \mathrm{~V}-10 \mathrm{~V}$ voltage, $100 \mathrm{~V}$ voltage is capable of causing a permanent damage of the components. In the case of electrostatic discharge, the voltage exceeds $5 \mathrm{kV}$ - discharge of this type, at improper dissipation of the charge, causes the majority of the damage in electronic components. The initial concept assumed transferring the progressive movement by a gearbox transmission joined with a trapezoid spindle translating the rotary motion of the motor into the progressive motion of the spindle. Such a concept assumed determining the pin stroke from the function of the revolutions of stepper motor. However, in the final version (Fig. 2), an electrical linear actuator DSZY4-12-50-100-IP65 with integrated DC motor powered by $12 \mathrm{~V} \mathrm{DC}$, with 50:1 ratio internal gearbox, $100 \mathrm{~mm}$ stroke and maximum force of $2500 \mathrm{~N}$ was selected. Application of a linear actuator guaranteed the possibility of adjusting the displacement speed within the range of $0.25-5 \mathrm{~mm} / \mathrm{s}$ for control voltage 0.5 to $12 \mathrm{~V}$, respectively, ensuring a more precise measurement.

The advantage of a linear actuator consists in the possibility of avoiding abrupt displacement which is an obvious effect of using a stepper motor with a gearbox. The application of a linear actuator eliminated impact loads during bending (smooth displacement) which contributed to obtaining more reliable results. A metal grip for 3-point bending was fixed to the main frame. The grip was made of $5 \mathrm{~mm}$-thick plate with guides allowing smooth adjustment of the rests span. Particular elements were joined with bolts, allowing for the modification and locking the setting of each element of the construction depending on the current needs.

Displacement sensor PELTRON PSz 50 with measurement range of $50 \mathrm{~mm}$ was fixed in parallel to the 

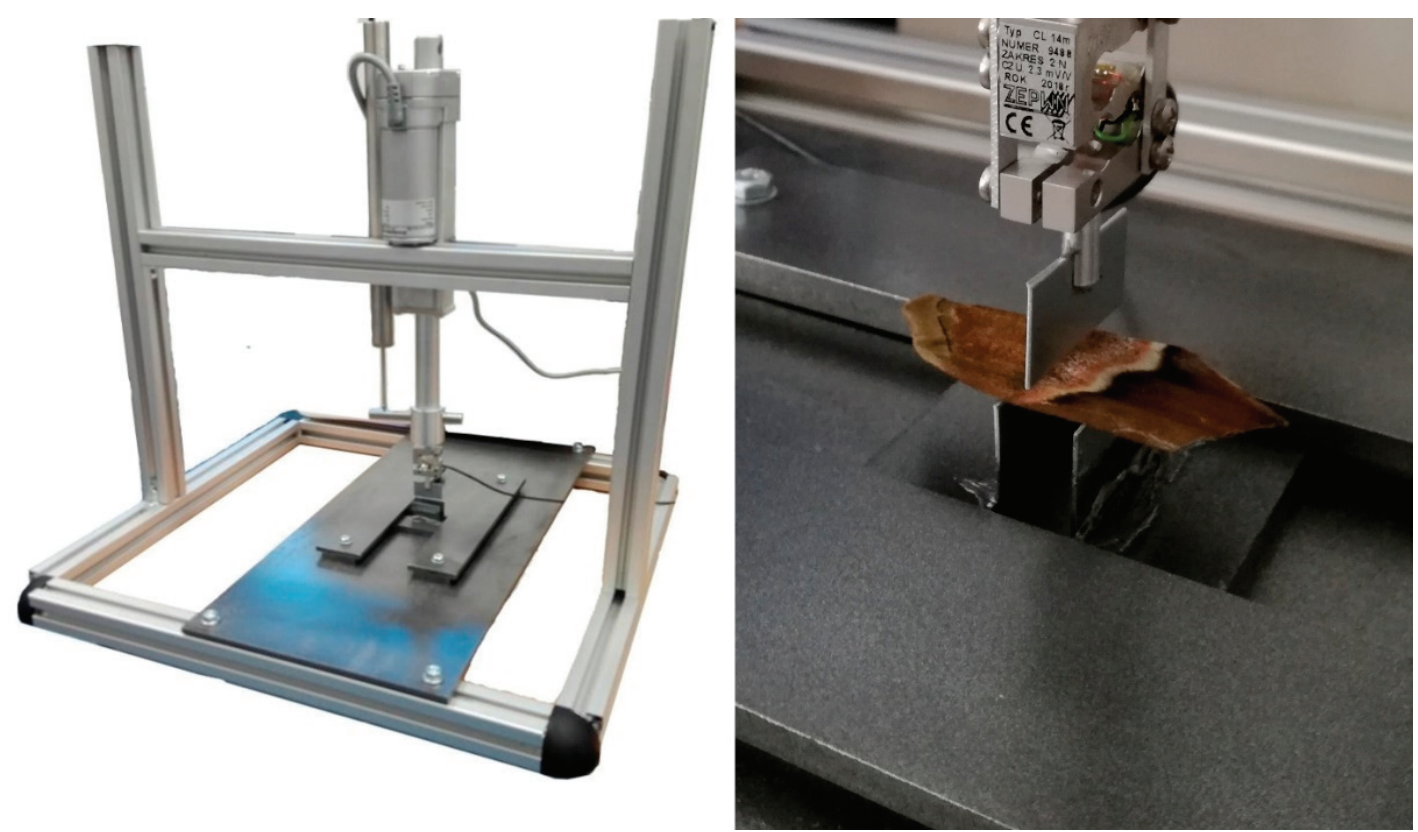

Fig. 2. Measurement station

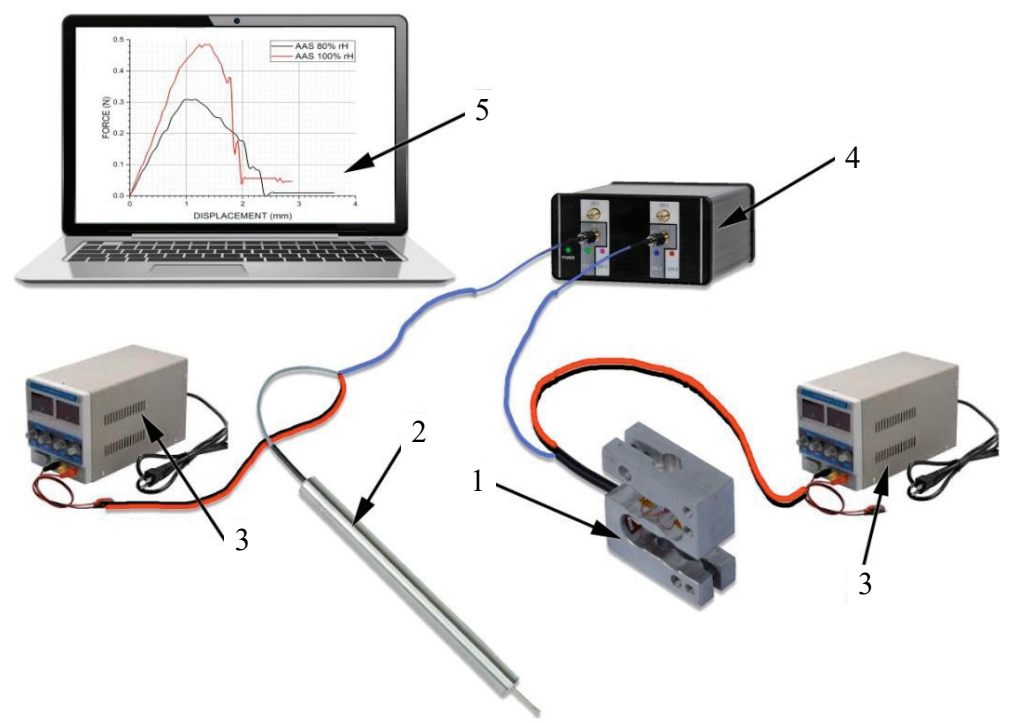

Fig. 3. Schematic drawing of the measurement system. 1 - force sensor, 2 - displacement sensor, 3 - stabilized power source, 4 - signal amplifier, 5 - computer with data acquisition software

linear actuator. Displacement transducer was built on the base of a differential transformer placed in a cylindrical housing, featuring a spring system allowing for contact measurements. Transducer housing contained an electronic component with output signal of $\pm 10 \mathrm{~V}$. The actuator was equipped with a tensometric S-shaped force sensor (for measuring the compressive and tensile forces) with a loading pin. Additionally, force sensor ZEPWN type CL14m, measurement range $2 \mathrm{~N}$ powered with stabilized current of $5 \mathrm{~V}$ and with $2 \mathrm{mV} / \mathrm{V}$ sensitivity was selected. Measurement station (Fig. 3) features a 14-bit data acquisition system and separate stabilized power supplies in order to avoid the interference of signals from particular channels.

Three species of insects, one species of three various orders of winged insects: butterflies, Hymenoptera bees and dragonflies were selected for the examinations:

- Attacus atlas (Fig. 4a) the largest representative of butterflies in the world. In the natural habitat it occurs in Ceylon, Malaysia, and China [2]. Specimens were obtained from a breeding farm;

- Vespa crabro (Fig. 4b) a representative of Hymenoptera bees, the largest representative of Vespidae in 
Poland. Its large wings facilitate the performance of the experiments; Libellula depressa (Fig. 4c) a common representative of Odonata (dragonflies) order widely spread in Poland.

All specimens originated from the insects bought from a breeder.

(a)

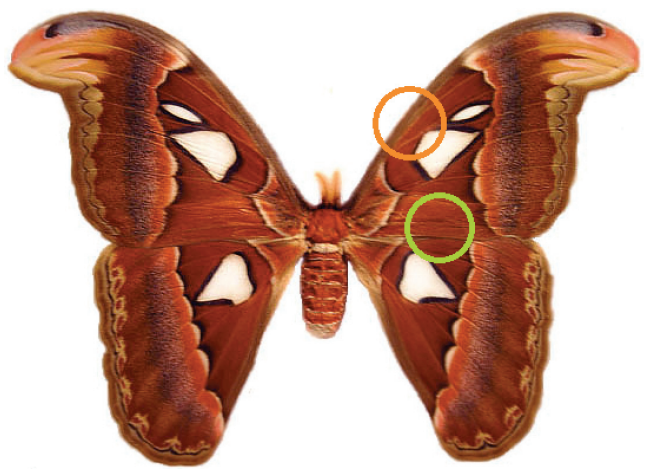

(b)

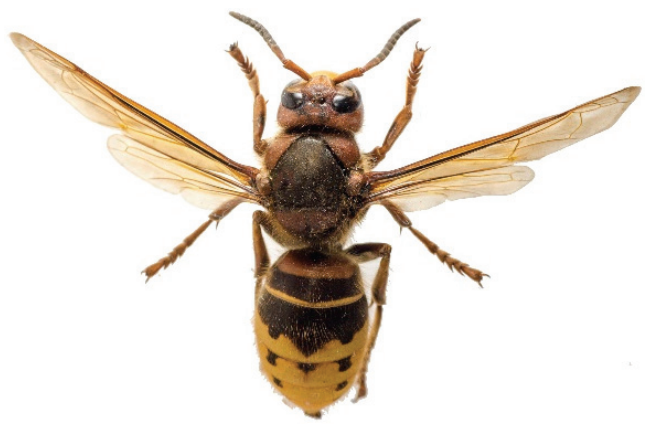

(c)

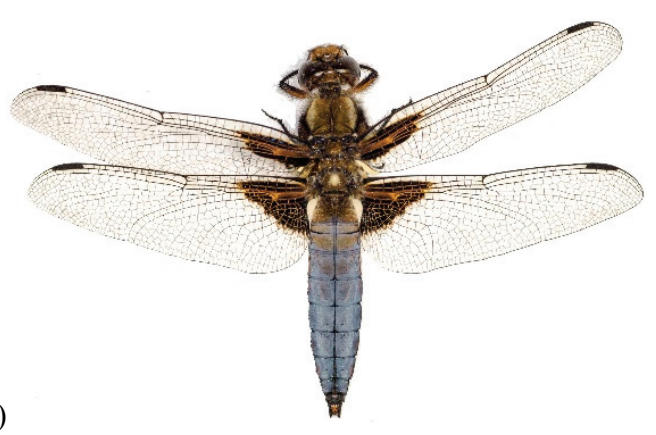

Fig. 4. Reference photographs of the examined insects:

(a) Attacus atlas, (b) Vespa crabro, (c) Libellula depressa

In the case of Vespa crabro and Libellula depressa, deformation of the whole wing was measured. The hind wing of Vespa crabro was too small (too low strength) and the bending forces were not registered. In the case of Attacus atlas, a section of the leading edge (Fig. 5a) and a section of the trailing edge (Fig. 5b) of a wing were examined. Sampling locations were marked in Fig. $4 \mathrm{~b}$ in red and green for leading and trailing edges, respectively. The examination of the butterfly wing membrane itself did not yield any effects: registered bending force equalled zero. The wing should have been divided into zones, since at such a large surface area, the mechanical properties exhibit significant differences depending on the location. Figure 5 shows examples of macro-photographs of the excised sections of wings which were the specimens under examination.

(a)

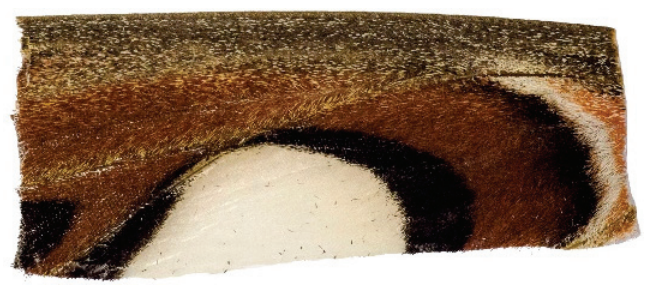

(b)

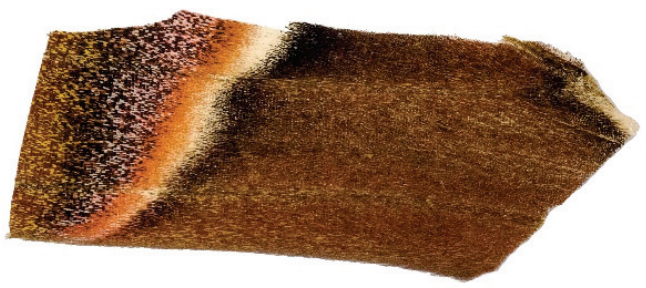

Fig. 5. Excised sections of the forewings of Attacus Atlas: a) leading edge (AAP_N_8), b) trailing edge (AAP_S_8)

Wing bending flexural stiffness was measured during the experiment by applying the force in the middle of the measurement section. The wing was being bent perpendicularly to its length. Examined specimens were placed on the rests freely, without any adhesive or clamps. The next stage consisted in slow lowering of the load pin to a level which was $2 \mathrm{~mm}$ above the specimen. Then, a stabilized power supply unit was used to set the voltage corresponding to the selected extension speed. In the next stage, the apparatus and data acquisition system were engaged and the voltage was supplied to the actuator. Force registration was initiated before the load pin contacted the wing and lasted until force value decreased after the break. The tested wing was unloaded by slow withdrawal of the load pin and it was put into safe storage with appropriate marking in order to examine the fracture with the SEM microscope. Power supply unit system was reset after each measurement and the correctness of the operation of force sensor was tested with three certified weighs: 1,2 and $5 \mathrm{~g}$.

The examination of the insects with more intricate or smaller wings, such as Tipulapadulosa or smaller species of dragonflies was impossible since the breaking forces would be so low that they would not be correctly recorded or not recorded at all. Registration of such forces would require constructing a testing station isolated from the air movement (air would influence the measurements) and equipped with force sensor with the range below $2 \mathrm{~N}$. The experiment was 
performed in three various air humidity conditions in order to simultaneously specify their influence on the mechanical parameters of biological materials for whose the conditions of the operating environment have a significant meaning. The majority of specimens was conditioned at $80 \%$ air humidity and $25{ }^{\circ} \mathrm{C}$ in Binder MKF 115 climatic chamber for over 24 hours. Air humidity of $80 \%$ reflects the condition of air prevailing for insects habitating in Poland. In comparison, the experiments included dragonfly wing specimens conditioned at approximately $98 \%$ and $30 \%$ air humidity. The humidity of air in the area where Attacus atlas is present reaches, approximately, 80-100\% [28]. The examination at $30 \%$ air humidity had only theoretical character as it was not aimed at simulating the natural conditions of the insects' habitats. It was only performed in order to compare the mechanical values which biological materials could have in extreme conditions.

Bending tests were performed with two various settings of the lower rests: 5 and $10 \mathrm{~mm}$ span:

$>$ For specimens of Attacus atlas and Libellula depressa: $10 \mathrm{~mm}$,

$>$ For Vespa crabro wing: $5 \mathrm{~mm}$.

\section{Results}

The measurements provided the relationship between the force and wing deflection. Figure 6 presents an example of the course of the force in the deflection function during the test of 3-point bending for specimens Attacus atlas leading edge in $80 \% \mathrm{rH}$ and $98 \%$
$\mathrm{rH}$ conditioning. The graph exhibits a varied inclination of the initial, straight line section of the curve, which indicates the differences in Young's modulus depending on the humidity.

On the basis of the example graphs of the force and displacement, it can be determined that the maximum forces obtained at bending Attacus atlas $(80 \% \mathrm{rH})$ specimen are lower than in the case of specimens conditioned at $98 \% \mathrm{rH}$. Assuming similar cross-sections of the wings, this indicates a decrease of the flexural strength of wings at lower humidity. During the tests of a dry wing $(30 \% \mathrm{rH})$ of Libellula depressa, a decrease of wing elasticity was noticed, there was a brittle fracture after maximum force was reached.

Fracture places of the wings and their surfaces were examined with Olympus BX52 light microscope. Figures 7-8 present the specific sections of the examined wings - their cross-sections and structure.

The structure of the wing surface of Lepidoptera insects differs significantly from other examined species. The difference is the most probable reason for varied susceptibility of the mechanical values to the changes in the humidity of the environment. Butterfly wings material is not as susceptible to the changes in the humidity. This is probably caused by the fact that the wings are covered with scales (Fig. 7a, b). The veins of the insects are made of chitin and their diameters are quite large in Attacus (Fig. 7c). In majority of cases, the veins remain hollow, while smaller diameter veins are filled with protein. Due to this solution, it was possible to achieve high flexural strength with simultaneous minimization of mass.
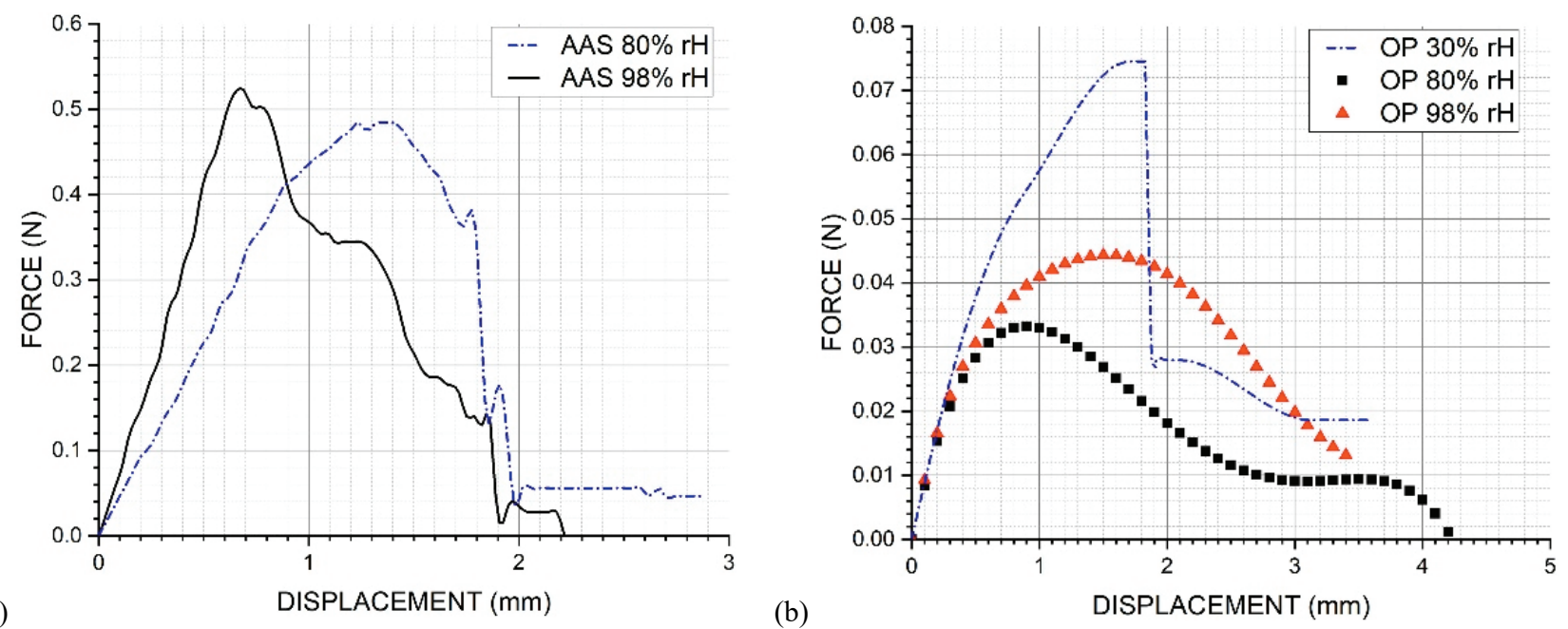

Fig. 6. Example graphs of the force and displacement in various humidity conditions:

(a) Attacus atlas, (b) Libellula depressa 



Fig. 7. Microscopic photographs: (a) Attacus atlas wing surface, section of a pink line,

(b) Attacus atlas wing surface, coloration change border, (c) Attacus atlas cross-section of the leading edge,

(d) leading edge, (e) Vespa crabro middle section of a wing, (f) Vespa crabro cross-section of the membrane,

(g) Libellula depressa cross-section of the forewing, (h) Libellula depressa surface of the forewing

Very thin wing membrane whose thickness is in the order of 1 micrometer in Vespa cabro is covered with small bristles (Fig. 7d, e, f). This is probably connected with braking off a boundary layer of fluid during dynamic motion of a flapping flight. However, a precise description of the phenomenon would require profound examinations. Transverse cross-section (Fig. $7 \mathrm{~g}$ ) of a dragonfly wing shows that the wing is not a flat surface. Curves shown in this figure have significant meaning for the aerodynamics of flight. In spite of the considerable differences in sizes, the veins in Libellula depressa also remain hollow. Figure $7 \mathrm{~h}$ presents a section of a wing with a stigma. This cell consists of two chitin walls and it remains hollow insde.

General stiffness of a wing is the product of material stiffness ( $E$, describing the stiffness of the wing material itself) and geometric inertia moment ( $I$, describing the stiffness generated by the geometry of the wing cross-section). In order to obtain Young's modulus after bending tests, it was necessary to obtain:

- flexion force $-F$,

- restsspan $-L$,

- deflection value $-s$,

- geometric inertia moment $-I$. 

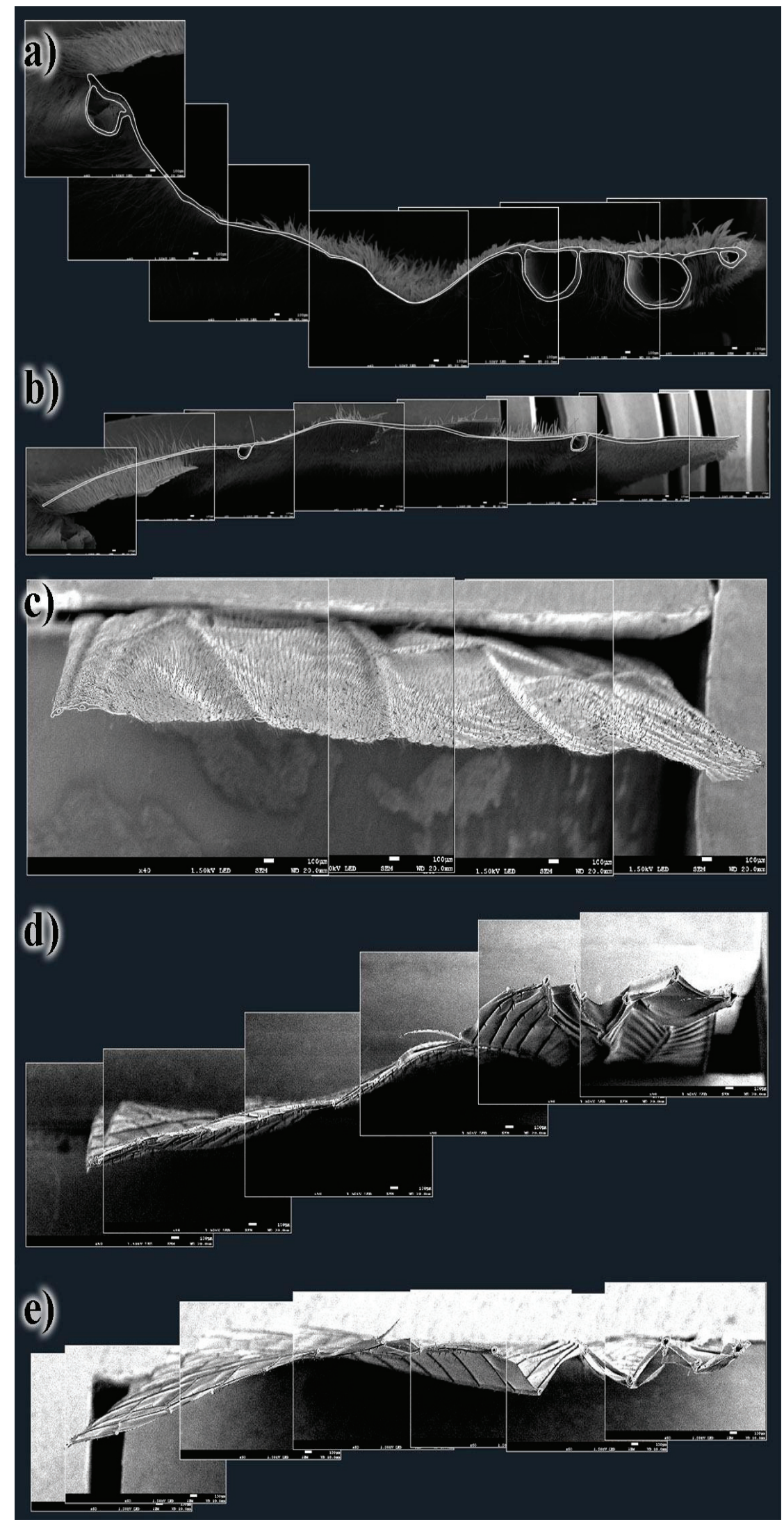

Fig. 8. (a) Cross-section of the specimen leading edge of Attacus atlas, (b) Cross-section of the specimen leading edge of Attacus atlas, (c) Cross-section of the specimen forewing of Vespa crabro,

(d) Cross-section of the specimen forewing of Libellula depressa, (e) Cross-section of the specimen hindwing of Libellula depressa 
The relationship between deflection value and force was derived from the results of the experiments. Young's modulus characterizes the stiffness of material within the range of elastic deformations following Hooke's law. In order to calculate Young's modulus, it was necessary to consider only the linear relation from the first section of the graph. Exceeding the range of the deformation and stress, proportionality is accompanied by non-reversible changes in the material - lasting deformation or rupture of the material continuity. The span of the rests was selected in relation to specific wings, set on the grip attached to the testing machine. The design of the measurement system allows smooth adjustment of the rests span, however, two settings were sufficient for the examined specimens. They were adjusted to the size of the specimens in such a way as to ensure, on one hand, that the specimen does not slide in between the rests (too big distance) and, on the other hand, to avoid or minimize the shearing stresses occurring instead of bending stresses when the span between the rests is too small.

Inertia moment, being the measurement of a body inertia in rotary motion in relation to specific rotation axis could not have been calculated manually. Taking the irregularity of the shape into consideration, manual division into geometric figures of known inertia moment, finding the center of gravity and calculations considering Steiner theorem, would not only be burdened with a significant error, but also would be impossible to perform with the extent of precision allowing the result which would not interfere with further calculations. Thus, inertia moments were calculated in AutoCAD software on the basis of the microscopic photographs (Fig. 8) of the transverse cross-sections of wings at the breaking point. Photos were taken with a scanning electron microscope Jeol JSM-7800F. The outline of the cross-section was drawn manually, the envelopes of particular veins were combined into a single object. Next, with "physical parameters" command, geometric inertia moment was calculated automaticly.
Table 1. Inertia moments for cross-sections in Fig. 8

\begin{tabular}{|l|c|}
\hline \multicolumn{1}{|c|}{ Cross-section } & $\begin{array}{c}\text { Geometric } \\
\text { inertia moment }\left[\mathrm{m}^{4}\right]\end{array}$ \\
\hline Attacus atlas forewing leading edge & $1.17 \mathrm{E}-13$ \\
\hline Attacus atlas forewing trailing edge & $1.51 \mathrm{E}-15$ \\
\hline Vespa crabro & $2.24 \mathrm{E}-17$ \\
\hline Libellula depressa forewing & $1.45 \mathrm{E}-15$ \\
\hline Libellula depressa hindwing & $2.07 \mathrm{E}-15$ \\
\hline
\end{tabular}

Next, Young's modulus was calculated with the formula (1) [11].

$$
E=\frac{F \cdot L^{3}}{49 \cdot s \cdot I}
$$

where:

$E$ - Young's modulus,

$F$ - pressure force,

$L-$ rests span,

$s$ - deflection value,

$I$ - geometric inertia moment.

The values of Young's modulus expressed in GPa for three various levels of air humidity are presented below (Table 2).

\section{Discussion}

In comparison with experiment results intervals, Young's modulus of other natural materials falls within the following intervals [19] (Table 3). The Young's modulus of biological materials, due to their often individual characteristics, is given in ranges. These ranges have a span of several GPa. For example, the Young's modulus of cotton is in the range of 8-35 GPa, and the coconut 4-6 GPa. In this context, the results of this study fall within the ranges of results of biological materials.

Table 2. Results of the calculations of Young's modulus [GPa] and its percentage decrease

\begin{tabular}{|l|l|c|c|c|c|c|c|}
\hline \multirow{2}{*}{ Insect } & \multicolumn{1}{|c|}{$\begin{array}{c}\text { Specimen } \\
\text { of wing }\end{array}$} & \multicolumn{3}{|c|}{ Humidity } & \multicolumn{3}{c|}{ Percentage decrease } \\
\cline { 3 - 8 } & & $30 \%$ & $80 \%$ & $98 \%$ & $30 \rightarrow 80$ & $80 \rightarrow 98$ & $30 \rightarrow 98$ \\
\hline \multirow{3}{*}{ Attacus atlas } & $\begin{array}{l}\text { forewing } \\
\text { leading edge }\end{array}$ & - & 0.35 & 0.32 & - & 8.99 & - \\
\cline { 2 - 8 } & $\begin{array}{l}\text { forewing } \\
\text { trailing edge }\end{array}$ & - & 7.45 & 6.54 & - & 12.20 & - \\
\hline Vespa crabro & forewing & - & 13.88 & 6.72 & - & 51.55 & - \\
\hline $\begin{array}{l}\text { Libellula } \\
\text { depressa }\end{array}$ & forewing & 1.81 & 1.65 & 0.86 & 8.98 & 47.64 & 52.34 \\
\hline
\end{tabular}


Table 3. Comparison of literature and experimental results range of Young's modulus

\begin{tabular}{|l|c|}
\hline Literature results range [19] & $\begin{array}{c}\text { Experimental results range } \\
(80 \% \mathrm{rH})\end{array}$ \\
\hline - balsa: 0.04-0.5 GPa, & $\bullet$ Attacus atlas forewing \\
- bamboo: 3-70 GPa, & leading edge: $0.09-0.86 \mathrm{GPa}$ \\
- chitin: $40-90 \mathrm{GPa}$, & Attacus atlas forewing \\
- cotton: $8-35 \mathrm{GPa}$, & Vespa crabro: $6.86-22.44 \mathrm{GPa}$ \\
- apple skin: $0.06-0.08 \mathrm{GPa}$, & Vedge: $4.65-11.25 \mathrm{GPa}$ \\
- leather: $0.007-0.08 \mathrm{GPa}$, & Libellula depressa forewing: \\
- eggshell: $11-40 \mathrm{GPa}$. & $0.27-3.75 \mathrm{GPa}$ \\
& Libellula depressa hindwing: \\
& $0.42-2.48 \mathrm{GPa}$ \\
\hline
\end{tabular}

Natural materials are characterized by considerable differences in mechanical parameters. Also, in the case of Young's modulus, lower and upper extremes yield a large interval. This results partially from the measurement errors, but mostly from the individual features of each specimen and each creature (or individual). This is the reason why it is necessary to average the data and results in order to perform further analyses.

During the described experiments, measurements yielded average values of Young's modulus for various wings and at different humidity conditions. Subsequently, percentage decrease of Young's modulus at the change of humidity was calculated. This way yielded a surprisingly repeatable result. When the value of air humidity changes from 80 to $98 \%$, the decrease is approximately $10 \%$ for Lepidoptera insects and approximately $50 \%$ for the remaining wings specimens. Table 2 contains the precise data on the percentage decrease of Young's modulus at the change of humidity level. The difference in the susceptibility to the change of humidity level should be detected in the structure of the wing. It transpires that covering the wings with scales significantly influences the wing mechanical properties and their change depending on the environmental conditions.

\section{Conclusions}

Essentially, the material of insects wings is exceptionally complex and its properties are unique and ontogenetic. Nevertheless, performed examinations indicated that it is possible to determine an approximate Young's modulus if the wing is treated as a uniform material without determining the mechanical parameters of particular cells, veins or scales. It is indeed a certain approximation, however, it is necessary since the measurement of such small elements would be burdened with significant error and, what is more, would not have a considerable meaning for flight mechanism because the entire composite is engaged in the flight physics. Therefore, for the needs of this and the following research (e.g., on the flapping flight mechanism) it should be assumed that an insect wing is a uniform material of specific properties. Modelling of the particular parts of the structure would be pointless. Prospective clarification would be assuming the existence of the zones with various values of mechanical parameters. For example, in the case of large surface area of the wing of Attacus atlas, on the basis of the performed analyses, it is possible to determine various values of Young's modulus for the leading and trailing edges. However, it is impossible to examine the mechanical properties in a specific spot, because, for instance, the examined specimen needs to have a specific length. For this purpose, it would be sensible to assume the existence of a certain distribution of Young's modulus on the surface of the wing where the zones which were not measured directly would have values approximated on the basis of the measured ones. However, this will still be an approximation. Each attempt of recognition and mathematical description of nature needs to produce an approximation since we are only mimicking solutions which proved to be the best in the course of evolution.

\section{Funding}

The project was financed from the Dean's grant entitled Examination of the mechanical properties of insect wings at Faculty of Power and Aeronautical Engineering approved for realization in 2017/2018 and NCN Grant "Preludium" No. 2014/ $15 / \mathrm{N} / \mathrm{ST} 8 / 00769$.

\section{References}

[1] Arjangpay A., Darvizeh A., Yarmohammad Tooski M., ANSARI R., An Experimental and Numerical Investigation on Low Velocity Impact Response of a Composite Structure Inspired by Dragonfly Wing Configuration, Composite Structures, 2017, (184), 327-336, DOI: 10.1016/ j.compstruct.2017.10.006.

[2] Carter D.J., Greenway F., Butterflies and Moths, Dorling Kindersley, 2002. ISBN: 978-o-7894-8983-8.

[3] COMBES S.A., DANIEL T.L., Flexural stiffness in insect wings. I. Scaling and the influence of wing venation, J. Exp. Biol., 2003, 20617, 2979-2987.

[4] Di Zhang, Wang Zhang, Jiajun Gu, TongXiang Fan, QINGlei Liu, HuILANSu, ShenMin Zhu, Inspiration from Butterfly and Moth Wing Scales: Characterization, Modeling and Fabrication, Progress in Materials Science, 2015, (68), DOI: 10.1016/j.pmatsci.2014.10.003. 
[5] Dinwiddie A., Null R., Pizzano M., Chuong L., Leigh Krup A., Fe Tan H., Patel N.H., Dynamics of F-Actin Prefigure the Structure of Butterfly Wing Scales, Developmental Biology, 2014, (392) 2, DOI: 10.1016/j.ydbio.2014.06.005.

[6] Fauziyah S., Alam C., Soesilohadi R.C., Retnoaji B., Alam P., Morphological and Mechanical Characterisation of the Hindwing Nodus from the Libellulidae Family of Dragonfly (Indonesia), Arthropod Structure \&amp; Development, 2014, (43) 5, DOI: 10.1016/j.asd.2014.06.004.

[7] Gemmer T.R. et al., Hopper/Entomopter Tandem System for Surface and Subsurface Exploration of Mars, Concepts and Approaches for Mars Exploration, 2012, Vol. 1679.

[8] Gullan P.J., Cranston P.S., The Insects: an Outline of Entomology, Wiley-Blackwell, 2014, ISBN-13: 978-1444330366.

[9] Ha N.S., JIN T.L., Goo N.S., PARK H.C., Anisotropy and nonhomogeneity of an Allomyrina Dichotoma beetle hind wing membrane, Bioinspiration and Biomimetics, 2011, (6) 046003, DOI: 10.1088/1748-3182/6/4/046003.

[10] Ha Ngoc San, Truong Quang Tri, Phan Hoang Vu, Goo NAm Seo, Park Hoon Cheol, Structural Characteristics of Allomyrina Dichotoma Beetle's Hind Wings for Flapping Wing Micro Air Vehicle, Journal of Bionic Engineering, 2014, (11) 2, DOI: 10.1016/s1672-6529(14)60038-x.

[11] Halliday D., Resnick R., Krane K.S., Physics. Part Two, Wiley, 2016, ISBN: 978-1-119-07707-7.

[12] Hasan J., Roy A., Chatterjee K., Yarlagadda P.K., Mimicking Insect Wings: The Roadmap to Bioinspiration, ACS Biomaterials Science \& Engineering, 2019, 5 (7), 3139-3160.

[13] Huainui Ren, Xishu Wang, Xudong Li, Yinglong Chen, Effects of Dragonfly Wing Structure on the Dynamic Performances, Journal of Bionic Engineering, 2013, (10) 1, DOI: 10.1016/S1672-6529(13)60196-1.

[14] Jin T.T.. Goo N.S., Sung-ChOONG Woo, PARK H.V., Use of a digital image correlation technique for measuring the material properties of beetle wing, Journal of Bionic Engineering, 2009, (6) 3, DOI: 10.1016/S1672-6529(08)60105-5.

[15] Jongerius S.R., LenTink D., Structural Analysis of a Dragonfly Wing, Experimental Mechanics, 2010, (50) 9, DOI: 10.1007/s11340-010-9411-x.

[16] Katunin A., Krukiewicz K., Herega A., Catalanotti G., Concept of a conducting composite material for lightning strike protection, Advances in Materials Science, 2016, 16 (2), 32-46.

[17] Le Roy C., Debat V., Llaurens V., Adaptive evolution of butterfly wing shape: from morphology to behavior,
Biological Reviews, 2019, (94) 4, DOI.org/10.1111/ brv. 12500 .

[18] Liu Z., YAn X., Qi M., Zhu Y., HuAng D., Zhang X., Lin L., Artificial insect wings with biomimetic wing morphology and mechanical properties, Bioinspiration \& Biomimetics, 2017, 12 (5), 056007.

[19] Meyers M.A., Po-Yu Chen, Yu-Min Lin, Yasuaki Seki, Biological Materials: Structure and Mechanical Properties, Progress in Materials Science, 2008, (53) 1, DOI: 10.1016/ j.pmatsci.2007.05.002.

[20] Rajabi H., Ghoroubi N., Darvizeh A., Appel F., Gorb S.N., Effects of multiple vein microjoints on the mechanical behaviour of dragonfly wings: numerical modelling, Royal Society open science, 2016, 3, 150610, DOI: 10.1098/rsos.150610.

[21] Rajabi H., Ghoroubi N., Darvizeh A., Dirks J.H., ApPel E., GORB S.N., A comparative study of the effects of vein-joints on the mechanical behaviour of insect wings: I. Single joints, Bioinspiration and Biomimetics, 2015, 10 (5), DOI: 10.1088/ 1748-3190/10/5/056003

[22] Schroeder T.B., Houghtaling J., Wilts D.D., Mayer M., It's not a bug, it's a feature: functional materials in insects, Advanced Materials, 2018, (30) 1705322, DOI: adma.201705322 1705322.

[23] Shang J.K., Combes S.A., Finio B.M., Wood R.J., Artificial insect wings of diverse morphology for flapping-wing micro air vehicles, Bioinspir. Biomim., 2009, 4, 036002.

[24] Shichao Niu, Bo Li, Zhengzhi Mu, Meng Yang, Junqiu Zhang, Zhiwu Han, LuQuan Ren, Excellent StructureBased Multifunction of Morpho Butterfly Wings: A Review, Journal of Bionic Engineering, 2015, (12) 2, DOI: 10.1016/ s1672-6529(14)60111-6.

[25] Sivasankaran P.N., Ward T.A., ViYapuri R., Mohd J.R., Static Strength Analysis of Dragonfly Inspired Wings for Biomimetic Micro Aerial Vehicles, Chinese Journal of Aeronautics, 2016, (29), 2, DOI: 10.1016/j.cja.2016.02.007.

[26] Sun Jiyu, Bhushan B., The Structure and Mechanical Properties of Dragonfly Wings and Their Role on Flyability, Comptes Rendus Mécanique, 2012, (340) 1-2, DOI: 10.1016/ j.crme.2011.11.003.

[27] Wehmann H.N., Heepe L., Gorb S.N., Engels T., LEHMANN F.O., Local deformation and stiffness distribution in fly wings, Biology open, 2019, 8, bio038299, DOI: 10.1242/bio.038299.

[28] www.worldweatheronline.com 